\title{
Kaposi sarcoma in South African children
}

\author{
Cristina Stefan ${ }^{1 *}$, David Stones ${ }^{2}$, Linda Wainwright ${ }^{3}$, Rob Newton ${ }^{4}$ \\ From $12^{\text {th }}$ International Conference on Malignancies in AIDS and Other Acquired Immunodeficiencies \\ (ICMAOI) \\ Bethesda, MD, USA. 26-27 April, 2010
}

\section{Background}

The AIDS epidemic has contributed to an abrupt increase of the incidence of Kaposi sarcoma, especially in Sub-Saharan Africa, to values tens of times higher than in the pre-epidemic era. There is, however, very little literature concerning the clinical features of this disease and its management and outcome in HIV-positive children in Africa.

\section{Aim}

To examine retrospectively a series of 70 HIV-positive children with Kaposi sarcoma, from several centers in South Africa, in order to describe the usual clinical presentation as well as the management and its impact on the course of the disease.

\section{Patients and methods}

Data were analyzed from tumor registries and patient records in four South African hospitals from January 1998 to December 2009.

\section{Results}

The average age in this series was 73 months. The ratio of males to females was 1,65 . The lesions were present on skin in 32 out of 63 cases $(50.79 \%)$, alone or in combination with other sites. In 8 cases $(12.69 \%)$ the tumor was localized exclusively in the mouth, in a further 8 patients $(12.69 \%)$ exclusively in the viscera, and in 6 patients $(9.52 \%)$ only in the lymph nodes. Tuberculosis was associated with Kaposi's sarcoma in 9 cases out of 38 (23.68\%). The mean CD4+ lymphocyte count was $440(\mathrm{SD}=385)$. Only 38 patients $(54.28 \%)$ were taking combined antiretrovirals at the time of diagnosis. Twenty-nine cases $(41.42 \%)$ received chemotherapy with
Bleomycine, Vincristine, and Adriamycin, alone or in combination. While 32 patients $(45.71 \%)$ died after an average of 4 months, the average followup period for the remaining children was 16 months, with a maximum of 57 months.

\section{Conclusions}

Most of the time the clinical diagnosis was suggested by the skin lesions; however, in a large percentage of cases the tumor was hidden in the mouth, viscera, or lymph nodes. The CD4+ lymphocyte count was not a predictor of Kaposi sarcoma. The mortality remains high in South Africa in spite of antiretroviral drugs and chemotherapy.

\section{Acknowledgements}

This article has been published as part of Infectious Agents and Cancer Volume 5 Supplement 1, 2010: Proceedings of the $12^{\text {th }}$ International Conference on Malignancies in AIDS and Other Acquired Immunodeficiencies (ICMAOI). The full contents of the supplement are available online at http://www.biomedcentral.com/1750-9378/5?issue=S1 .

\section{Author details}

${ }^{1}$ Department of Paediatrics and Child Health, Tygerberg Hospital and Stellenbosch University, Tygerberg, Cape Town, South Africa. ${ }^{2}$ Department of Paediatrics and Child Health University of Free State Universitas Hospital, Bloemfontein, South Africa. ${ }^{3}$ Department of Paediatrics and Child Health Chris Baragwanath Hospital, University of the Witwatersrand, Johannesburg, South Africa. ${ }^{4}$ Epidemiology and Genetics Unit, Department of Health Sciences, University of York, York, UK.

Published: 11 October 2010

doi:10.1186/1750-9378-5-S1-A43

Cite this article as: Stefan et al:: Kaposi sarcoma in South African children. Infectious Agents and Cancer 2010 5(Suppl 1):A43.

\footnotetext{
*Correspondence: cs@sun.ac.za

'Department of Paediatrics and Child Health, Tygerberg Hospital and

Stellenbosch University, Tygerberg, Cape Town, South Africa

Full list of author information is available at the end of the article
} 